\title{
Philosophical Dimensions in Sport
}

\author{
${ }^{1 .}$ Paul K. Wainaina $(\mathrm{PhD})$ and ${ }^{2,}$ Andanje Mwisukha $(\mathrm{PhD}$ \\ ${ }^{1,2}$ Kenyatta University Box 43844-00100, Nairobi, Kenya.
}

\begin{abstract}
Philosophy of Sport is a branch of Philosophy that seeks to conceptually analyze issues of sport as a human activity. It is concerned with questions and practical debates that arise in the context of sports. This branch of Philosophy originated in Ancient Greece with the advent of the Ancient Olympic Games. It utilizes non-empirical methods of philosophers to examine sport issues. The issues of sport fall in three philosophical categories that include metaphysics, ethics and moral philosophy, as well as political philosophy. Specifically, important questions that are explored in Philosophy of Sport relate to the nature, value, social virtues and morality in sports. Other related areas include mind-body holism, sexuality and gender, amateurism and professionalism, as well as the logic of rules in sport. By addressing questions in these areas, a better understanding of sport can be realized. This paper therefore, traces the historical development of Philosophy of Sport as an academic discipline and sheds light on the areas of philosophical debate in modern sport.
\end{abstract}

Key Words: Philosophy of Sport, Sport, Ethics, Morality, Political Philosophy, Metaphysics, Question.

\section{Philosophy Of Sport: A Historical Perspective}

Philosophy of Sport is a branch of Philosophy that seeks to conceptually analyze issues of sport as a human activity. Ancient Greece is considered the birthplace of both ancient Philosophy and Olympic Sport. The philosophical perspective on sport emerged in Ancient Greece some time during the $15^{\text {th }}$ century (Weiss, 1969). Hellenistic philosophies put great significance on athletic performance. For instance, a leader's athletic prowess, according to the view of the times, reflected their ability to lead (Kretchmar, 1994). Sport was seen as an epistemic inquiry, a methodological process by which people learnt the objective truth of a person's athletic potential by actualizing it in athletic competition. Athletics as a measure of individual worth was viewed as a cure to social inequality. Sport was also considered as an instrument for social education, with Plato, for instance, advocating the participation of women in sport for their moral enrichment. Indeed, Plato is considered the first philosopher on matters of sport as he began to make inquiry into the nature and value of sport. Aristotle, another Greek philosopher, also emphasized physical activity as an ethical responsibility. Mentions of sport were also found in the works of Socrates.

Philosophy of Sport as a discrete academic field became more rooted during the second half of the $20^{\text {th }}$ Century following the philosophical publications of Paul Weiss of Yale University and Howard Slusher (Kretchmar, 1994). Although Weiss was not an expert in matters of sport, his publications encouraged the philosophical world to start making deep inquiry into sport. As a step towards further entrenching of philosophy of Sport as a field of study, the philosophical Society for the Study of Sport (currently known as the International Association for the Philosophy of Sport - IAPS) was formed in the later part of the $20^{\text {th }}$ Century. Other progressive undertakings for the advancement of this field of study was the launching of the Journal of the Philosophy of Sport in 1974 and subsequent publishing of a variety of books and anthologies on the subject. Further growth of the discipline has been witnessed in the recent years in terms of increasing interest and scholarly contributions across the globe. All these developments give a clear reflection on the importance of the discipline in highlighting a deeper understanding of sport.

\section{The Scope Of Philosophy Of Sport}

Philosophy of Sport is concerned with the conceptual investigations, analysis and interrogation of key ideas and issues of sports and related practices (McNamee, 2003). It involves addressing questions and practical debates that arise in the context of sports. At its most general level, it is concerned with articulating the nature and purpose of sport. It utilizes non-empirical methods of philosophers to examine sport issues. It gathers insights from the various fields of philosophy as they highlight the appreciation of sports practices and institutions as well as generates substantive and comprehensive views of sport itself. Being a form of philosophical discourse, the philosophy of sport embodies the formal and contextual character for the parent discipline. Hence, the issues of sport that are analysed fall in three philosophical categories that include metaphysics, ethics and moral philosophy, as well as political philosophy. According to Reid (2012), a philosophical perspective on sports incorporates its metaphysical relationships with art and play, ethical issues of virtue and fairness, and more broadly, socio-politics of sports. Specifically, important questions that are 
addressed also focus on aesthetics of sporting performances and display, the epistemology of individual and team strategy and techniques as well as the logic of rules in sport.

McNamee (2012) summarizes the substantive issues in sport that are interrogated under the sub-fields of philosophy as follows:

i. Aesthetics: Is sport a form of art? Are Sports events works of art? Can we objectively evaluate sports action aesthetically?

ii. Epistemology: Can kinesthetic awareness properly be called knowledge? What precisely do we know when we are able to perform skills? Must a coach have performance knowledge at elite level to coach effectively at that level?

iii. Ethics: Does sport necessarily develop good character? What do we agree to when we agree to play a game? Is there such a thing as the ethos of sports?

iv. Logic (e.g. are sports separate from other spheres of logic by their nature? Are the concepts of sport and game logically discrete?)

v. Metaphysics (e.g. are humans naturally game playing animals?)

vi. Philosophy of Education: Can we morally educate people through sport? Is paternalism in sports coaching and teaching inevitable? What do we mean by the concept "sport skill"?

vii. Philosophy of law: Can children give consent to engage in elite sports training? Do rules underdetermine conduct?

viii. Philosophy of mind: Is mental training just a form of imagination? Are sportspersons simply to be thought of as machines?

ix. $\quad$ Philosophy of rules (e.g. are regulative sports rules just a species of constitutive ones?)

x. Philosophy of science: Is there such a thing as a singular method for all sciences? What does a sports scientist mean when they say a given statistical procedures has explanatory power?

xi. Social and political philosophy: Did a pure conception of sport ever exist in a given social and political time and order? Are sports competitions necessarily capitalistic in nature? Do sports institutions always corrupt pure play?

\section{Ethics of Modern Sport}

Ethical issues have attracted most of the scholarly debate within the field of philosophy of Sport. The ethical issues center on athlete behavior in relation to rules of the game, other athletes, spectators, external factors such as socioeconomic issues among supporters and communities, and to issues of doping (Reid, 2012). With the introduction and encouragement of professional sports in the modern world, as well as the rise of entertainment industry related to it, sport ethics has become a fertile terrain for testing and developing philosophical notions and theories.

\section{(a) Sport and Entertainment}

There is no doubt that sport is a very important part of peoples' lives in the modern world; it excites people from all walks of life. But the questions that arise in relation to the popularity of sport include: What is sport? Why is it an import human activity? Why does it excite people? Why do people watch it? Why do people spend so much of their time thinking about it? These questions bring to the fore the fact that there is something about sport that fascinates people but it is not entirely clear. Whereas there are many benefits from participating in sport, both physical and social, the experience of sport, most of the time, is through watching sport. Millions of people watch sport events in stadiums and on television screens. Hence, the benefits to health and wellbeing do not automatically transfer over to the spectators of sport; indeed the lives of sport spectators can be rather unhealthy, involving consumption of junk food, drinking and smoking.

Mumford (2013) argues that whereas many people watch sport for pure dumb entertainment, such sport spectatorship can be both a subject of high aesthetic values and valid source for moral education. This aspect of passive sports spectatorship provokes the question of how people should be positively and actively engaged in watching sport so as to enjoy its physical and health benefits.

\section{(b) Logic of Rules in Sport}

The other basic ethical question in sport is cheating in relation to breaking rules of the game. Sports are based on the fair enforcement of rules; every contestant (either an individual player or team) has an obligation to see that the rules of the game are applied in equal measure to every contestant, while also respecting the rules at all costs. Adherence to the rules has educational value in terms of teaching justice, inculcating a sense of respect for rules and laws of the wider society and the virtue of honesty. However, the philosophical questions that arise relate to whether a player can ever be justified in breaking the rules? In other words, is it ever morally permissible to intentionally break a rule? What if for instance breaking a given rule may offset some mistaken judgement or decision that a referee may have made earlier? What if breaking a rule 
may offset some economic, social or political inequities that may stand in between the contesting teams? Would such apparent points of justification for breaking rules be treated with lenience? Unwritten rules such as the custom in soccer of kicking the ball out of play when a player is injured might also carry some moral obligations; if a player fails to kick the ball out of play in a situation where he is supposed to do it, would he have done something wrong?

\section{(c) Aggression and Violence in Sport}

Morality in sports competitions also goes beyond rule-obedience. In completion, athletes must mutually seek excellence or victory that is ultimately "cooperative"; each should provide a good test for one's ability without causing harm (Simon, 1991). Violence, which can be viewed as the intent to harm or disable one's opponent is therefore, unethical because it interferes with the cooperative quest for excellence. What about the game of boxing where knocking-out of an opponent is part of competition? Is it ethical to violently disable one's opponent by knocking him out? The aggressive but clean checking in hockey may be part of the game, but preventing a competitor from being able to test his skills may not be acceptable.

\section{(d) Fair Compensation and Sport}

Following the shift from amateur to professional sport in the $20^{\text {th }}$ Century, most of the athletes compete for money but not for the love of the sport. With the increasingly high salaries of certain athletes, there is need to re-think the issue of just compensation for athletes. For instance, what would be the just compensation of players at different levels of competition? Should salaries of athletes be capped to control the large amounts paid to some while others receive meager pay? Is it morally right to pay alarmingly high salaries to some athletes but not to others? Should all athletes be compensated for competing?

\section{(e) Luck and Responsibility in Sports Performance}

Issues of attributing losses and victories in sport competition to luck or mistakes made by individual players are common in sports. Such issues are of ethical nature and generate a number of philosophical questions. For instance, who is to blame if a team loses a game? Is it the coach? Is it the whole team? The player who missed several shots? The player who committed several fouls? Is it morally right to blame an individual when a team loses? If a team wins in the last minutes of competition, would that be attributed to luck? In such instances, the boundaries between individual or collective merit and luck are often blurred so that the criteria for responsibility are disputable.

\section{(f) Doping in Sport}

Another ethical issue that has attracted scholarly debate in sport is doping or use of performance enhancers. Issues of doping focus on the ethics of medical intervention on athletic performance in terms of what is acceptable against what is not and how intelligent boundaries can be drawn between the two (Reid, 2012). Particular attention ought to be given to the question of what principles or considerations are put into account when banning the use of certain performance enhancers or medical interventions but not others. The morality of doping may be approached from the perspective of traditional virtue ethics which focus on the concept of sportsmanship; the view that a competitor must be fair, forthright and respectful of others' rights, and the corresponding question is whether such a person would engage in doping (Simon, 1991; Morgan, 2006). From a consequentialist utilization perspective, one may argue that doping the negative health consequences and is therefore morally unacceptable (Morgan, 2006). In recent years, the Social Practice Theory looks at sports as group activities in which participants seek certain internal goods and uphold particular standards of virtue. Given this perspective, the question about doping is whether it interferes with the pursuit of those internal goods or group-defined virtues.

In view of the professionalization of sport in the modern world, every professional athlete seeks medical and nutritional techniques that can enhance his/her performance. This has, on one hand, contributed to spectacular sportive results which add to the enthusiasm and entertainment side of sport but this raises the question of whether this outweights the effect of such performance enhancers on the health of the athletes? Another related issue is in terms of addressing the question of ways in which the performance enhancers affect the relationship or harmony between body and soul among athletes. An athlete's desire to use drugs may lead to spectacular performance but probably adversely affect his/her health, while failure to use the drugs may preserve health but deny the athlete the desired spectacular performance (so, which is the most appropriate option for the athlete in this case?).

Other issues relating to doping include the following: if some sports are extremely dangerous and even life-threatening, what is wrong with using performance enhancing drugs if they are also equally dangerous? And even if performance enhancing drugs are dangerous, it is not for the athletes themselves to abstain from using them rather than someone else banning them? If performance enhancing drugs are "unnatural", why should they 
be banned yet other unnatural items such as high-tech sports equipment (including hydrodynamic swimsuits, fiberglass vaulting pole, etc) continue to be used in sport competitions? Should the use of the hi-tech equipment be equally banned? Hi-tech equipment may interfere with the good of the sport if, for instance, it make the sport too expensive thereby locking out many athletes from participating in the sport or if it gives mechanical advantage to the athlete.

\section{Social and Political Functions of Sport}

The social and political functions of sport is another important area of philosophical speculation in sport. Sport is discussed as a means of moral education in terms of its ability to understand and shape character (Kretchmar, 1994). Reid (2002) also discusses on how athletes can learn from participating in competitive sport. The role of sport as a means of social education in terms of inculcating the virtues of cooperation, respect for rules/law, teamwork is another area of philosophical debate. Further, given the aggressiveness displayed in sport, can it really serve as an instrument for relaying moral and social education?

Since sport has had a history of exclusion by class, race and gender, to what extent can it be relied upon to bring about social equality in society? The question of gender imbalance in sport participation and leadership has often been debated over the years. Gender imbalance that is prevalent in sport, coupled with racial dominance in some of the sports as well as apparent discrimination of people of some classes in some sporting activities raises questions on the ability of sport as a means for social and moral education.

Sport is also discussed in terms of political concepts such as the social contract. For instance, do athletes enter a social contract by accepting to adhere to the rules of game? The political ideal of justice and equal opportunity in sports are reflected in sports by having common rules, starting lines and level playing fields but they area also challenged in terms of inequities in natural abilities of athletes, training and coaching resources, equipment and economic imbalances across various countries. Is it fair and logical for underdeveloped, developing and developed countries to compete on same level given their varied economic empowerment?

Another political dimension of sport is reflected in the idea that athletes competing in international competitions serve as "ambassadors" of their respective countries (Connor, 2011). For instance, victory of a soccer team in the World Cup can create the enthusiasm and excitement of the citizens of the mother country thereby enhancing the spirit of patriotism and nationhood. However, how does this on the hand impact on the human quest for international cooperation and integration? Does sport therefore, serve as an obstacle to promotion of international brotherhood?

\section{Conclusion}

Arising from the many sport issues that need to be debated, philosophy of sport should be treated as an academic discipline that has a lot of potential for exploration. Although many ideas from the history of philosophy have been widely applied to sport, there are still many others to be addressed. There is still much more to be interrogated and known about the nature, ethics, social and political angles of sport.

\section{References}

[1]. Conner, S. (2011): A Philosophy of Sport, Reaktion Books.

[2]. Reid, H. (2012): Introduction to the Philosophy of Sport. Rowman and Littlefield Publishers.

[3]. Kretchmar, R.C. (1994): Practical Philosophy of Sport. Champaign IL, Human Kinetics.

[4]. Kretchmar, R.C.(1996): Philosophy of Sport. In: Massengale, John D and Swanson, Richard A.

[5]. The History of Exercise and Sport Science. Champaign IL, Human Kinetics.

[6]. Morgan, W.(2006): Why Sports Morally Matter. New, York, Routledge.

[7]. Reid, H. (2002): The Philosophical Athlete. Durban, NC, Carolina Academic Press. 